\title{
Unique Magnetic Attachment Designed for a Solitary Dental Implant Retaining Silicone Nose Prosthesis
}

\author{
Satyabodh S Guttal ${ }^{1 *}$, Blessy S Bangera ${ }^{2}$, Adarsh Kudva ${ }^{3}$, Basavaraj R Patil ${ }^{4}$ and Srinath Thakur ${ }^{1}$ \\ ${ }^{1}$ Department of Prosthodontics, SDM College of Dental Sciences and Hospital, India \\ ${ }^{2}$ A.J Shetty Dental College, India \\ ${ }^{3}$ Oral and Maxillofacial Departement, Manipal Dental College, India \\ ${ }^{4}$ General Surgeon, R.B. Patil Cancer Hospital and Research Institute, India
}

*Corresponding author: Satyabodh S Guttal, Department of Prosthodontics, SDM College of Dental Sciences and Hospital, Dharwad 580 009 Karnataka, India, Tel: +9886754632; Fax: 305-243-4535; E-mail: drsatyabodh@yahoo.co.in

Received date: January 12, 2016; Accepted date: February 12, 2016; Published date: February 19, 2016

Copyright: ( 2016 Guttal SS, et al. This is an open-access article distributed under the terms of the Creative Commons Attribution License, which permits unrestricted use, distribution, and reproduction in any medium, provided the original author and source are credited.

\begin{abstract}
Midfacial defects are enormous defects that result from cancer treatment that rarely are corrected by surgical reconstruction alone; they generally require a facial prosthesis to restore function and appearance. Surgical reconstruction may be viable for few defects, which are done with different flaps. But for the total nasal resection, prosthetic option would be more feasible. Nasal cartilaginous anatomy is complex due to the varying contours. Therefore it may be difficult for the surgeon to reconstruct the entire nose. This clinical report describes the rehabilitation of a large mid-facial nose defect with a dental implant retained nasal prosthesis. The patient had adenocystic carcinoma of the medial maxillary wall extending to the nose.
\end{abstract}

Keywords: Maxillofacial prosthetics; Silicone prosthesis; Nasal defect

\section{Introduction}

The face being the most noticeable part of the body when disfigured may lead to an impaired social life stemming from esthetic problems $[1,2]$. Among facial defects, nasal defects produce severe cosmetic impairment. Rehabilitation of such defects subsequent to surgery is done in a sequential manner, which includes a surgical, provisional, and definitive prosthesis [3]. Prosthesis helps restore the patients' selfesteem and confidence, hence affecting the patients and their life style [4-6].

Adenoid cystic carcinoma (ACC) is a rare malignant perineural tumour of the major and minor salivary glands, accounting for $2 \%$ of all head and neck malignancies and approximately $10 \%$ of all salivary gland neoplasms. $60 \%$ to $70 \%$ of ACC's arise in the minor salivary glands, which may be localized in the palate, paranasal sinuses and nose, although they may also occur in the parotid or submandibular glands [7].

In the past, nasal prostheses were held in position with strings or straps fastened behind the head, [8] intranasal or intraoral extensions, $[9,10]$ and gold strings or leaves [11]. Spectacle frames have been accepted for securing nasal prostheses [12,13]. Today, with the development of biomaterials, prosthetic substitutes are secured with readily available adhesives that are effortlessly applied [14] however, the effectiveness of adhesives is questionable considering presence of mobile tissues in the defect, nasal secretions, and moist air associated with respiration [15]. These factors would compromise the adhesiveness. The concept of osseointegration [16] has enabled a more reliable mode of retaining nasal prostheses [17]. This clinical report describes the rehabilitation of a large midfacial defect using an implant retained nasal prosthesis.

\section{Case Report}

A 63-year-old female patient who reported to the B.R Patil Cancer hospital, Navanagar, Dharwad was diagnosed with adenocystic carcinoma of the medial maxillary wall. Patient had no medical comorbidity. Patient gave history of nasal obstruction due to nasal mass on left side of the nostril for which medial maxillectomy was done via endoscopic approach in the year 1993. Then in 2012 she reported back with the complaint of nodular swelling over nasal dorsum with tearing and nasal obstruction with no orbital symptoms. Intra-orally patient had destruction of palate on the left side crossing midline. Upon further investigation, biopsy revealed adenocystic carcinoma of the nose and left maxilla with no involvement of orbit or anterior skull base (Figure 1).

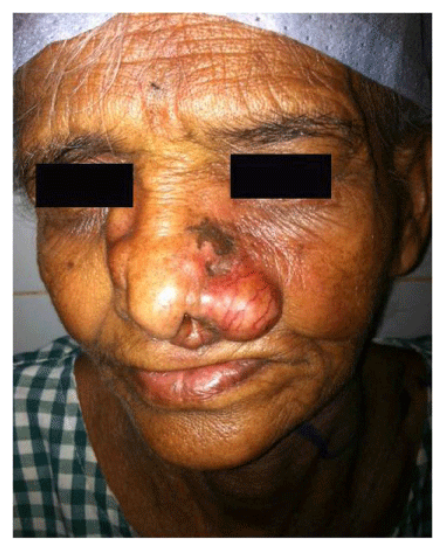

Figure 1: Preoperative patient photograph. 
Citation: Guttal SS, Bangera BS, Kudva A, Patil BR, Thakur S (2016) Unique Magnetic Attachment Designed for a Solitary Dental Implant Retaining Silicone Nose Prosthesis. Anaplastology 5: 157. doi:10.4172/2161-1173.1000157

Page 2 of 3

Surgical removal of the cancer affected nasal part and total maxillectomy of left side was done. This resulted in a huge midfacial surgical defect. Prosthetic rehabilitation was planned to close the huge defect. Since an immediate definitive prosthesis was not feasible, the patient was suggested for temporary rehabilitation with an interim silicone nasal prosthesis with an attached eyeglass frame. She was given the option of implant-retained definitive silicone nose prosthesis. The patient agreed for the same. An orthopantomograph and computerized tomography scan were made as a part of the investigation to evaluate the bone height for implant placement.

A Titanium dental implant with 4.2 diameters $\times 6.5 \mathrm{~mm}$ length was placed in the glabellar bone immediately after the surgical resection on the operation table. The glabellar bone was evaluated on the operation table and upon conclusion that adequate bone was available; a single implant of 4.2 diameter $\times 6.5 \mathrm{~mm}$ length, (Toureg S; Adin implants, Nazareth, Israel) was placed (Figure 2).

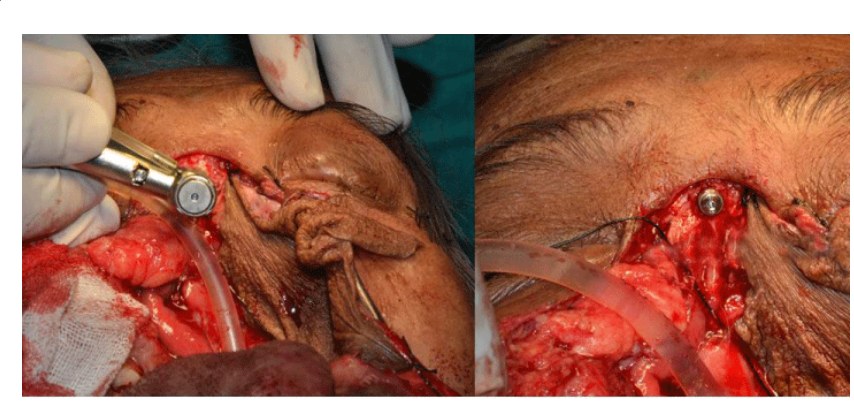

Figure 2: Placement of titanium dental implant in the glabella.

The advantage of placing the implant on the operation table was that the patient would be under general anesthesia, and the psychological trauma of undergoing another surgical procedure was avoided.

Following a healing period of 3 months the open tray impression posts were placed and the final impression was made. The abutment was placed on the implant and a custom made acrylic sleeve was fabricated for the abutment (Figure 3).
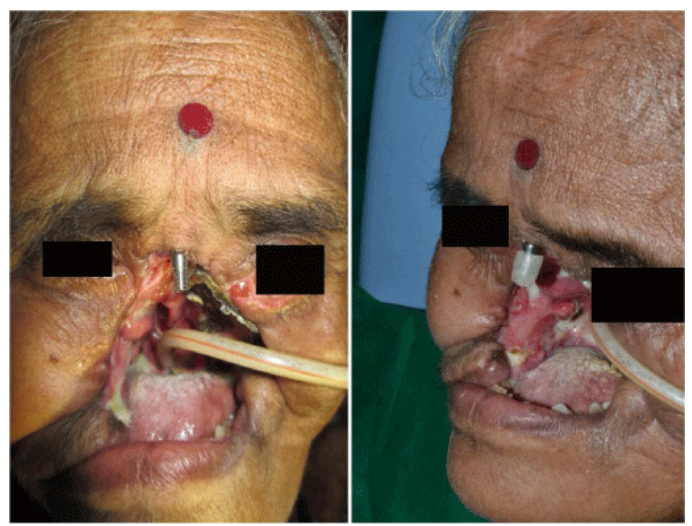

Figure 3: Abutment threaded to implant and the trial of acrylic resin sleeve done.

A wax sculpted nose on the master cast was made to adapt to the margins of the healing wound. On either sides of the acrylic resin sleeve, two neodymium-iron-boron magnets, $5 \mathrm{~mm}$ diameter $\times 1.2$ $\mathrm{mm}$ thick (Magnatech; Mumbai, India) were embedded into extensions made out of autopolymerising resin. The structure hence resembled a winged sleeve which was cemented on to the abutment using zinc-phosphate cement (Harvard Dental, Hoppegarten, Germany) (Figure 4).

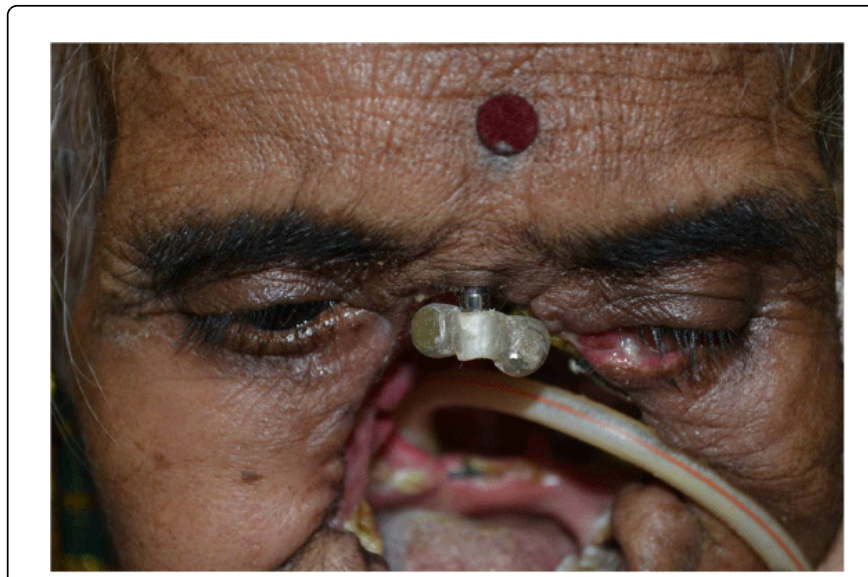

Figure 4: Cemented acrylic resin framework embedded with magnets on either side.

An acrylic resin index was fabricated over this structure which would harbor the respective magnetic keepers. The acrylic index was placed at its position over the magnets and was picked up by the wax nose that was placed on it using a drop of cyanoacrylate. The resulting wax nose thus incorporated an acrylic index with the magnetic keepers. This wax nose was carefully invested and the packing procedure using silicone and acrylic resin border framework, intrinsic colouring was carried out as mentioned for the interim above. Extrinsic colouring and pigmentation was done and patient was happy with the esthetical results. Digital weighing scale revealed that the definitive nasal prosthesis weighed around 12.2 gms. The retentive force offered by the two neodymium-iron-boron magnets (Magnatech; Mumbai, India) was found to be $7.2 \mathrm{~N}$. The prosthesis was delivered to the patient (Figures 5 and 6).

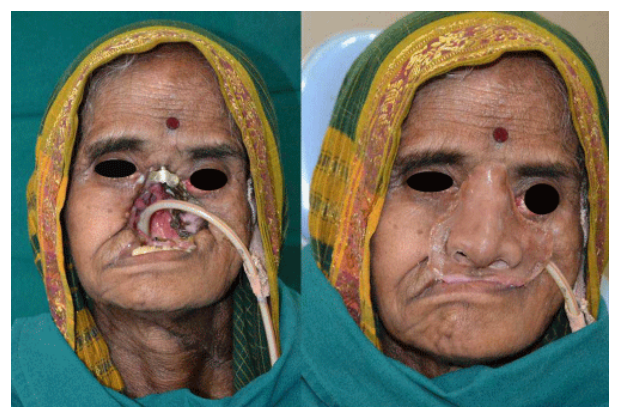

Figure 5: Comparison between before and after prosthesis placement. 
Page 3 of 3

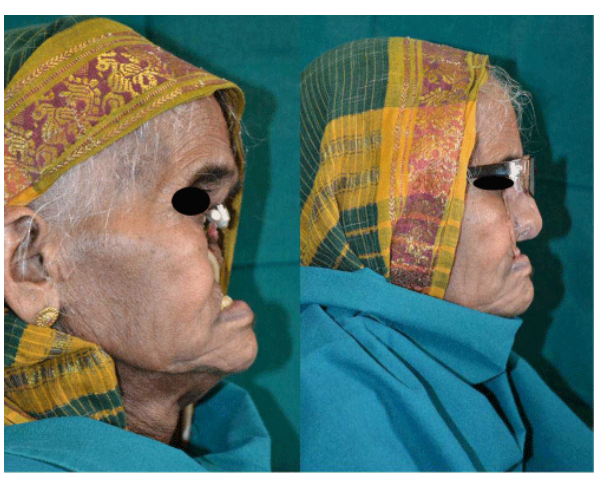

Figure 6: Lateral profile of before and after prosthesis placement. Spectacle glasses were given to camouflage the borders of the prosthesis.

Following this, home-care instructions were given. In the subjective evaluation, the patient was very happy with the esthetics outcome of the prosthesis and expressed her great pleasure towards her ability to swallow liquids. The ryles tube continued to remain in place considering the general health condition of the patient and the need to feed semi solid food and protein supplements. The prosthesis was light in weight and could be comfortably placed in position as it was selfaligning due to the use of magnets. Patient, who is now on regular periodic follow-up i.e., recalling at every 3 month period, is found to be doing well.

\section{Discussion}

Nasal reconstruction modalities comprises of primary closure, healing by secondary intention, skin grafts and local flaps and regional flaps. Small surgical defects can be treated well with different types of local flaps. The forehead flap is the better option for the large nasal defects. The complex anatomical configuration may cause difficulty in surgical rehabilitation. In such cases, prosthetic closure is predictable and hence usually the treatment of choice [18]. The breakthrough for rehabilitation of facial defects with implant-retained prostheses came with the development of the modern silicones and bone anchorage $[19,20]$.

The limitations of the prosthesis were explained to the patient prior to the treatment, that fact that the prosthesis would enhance esthetics but would contribute less to the functions like speech and masticatory habits. Hence, the patient had no psychological set back on the prognosis of the treatment. In addition, there was a major set-back in terms of achieving outstanding esthetical and functional outcome due to the fact that all the work was carried out under technical constraints. This included a lack of time, chair-side patient availability, and ideal light conditions which, to an extent precluded optimal colour blending.

The main objective of treating this case was to close the open defect, to prevent the further spread of infection in the soft tissues exposed to the environment. The use of a magnetic attachment assembly provided sufficient retention for the prosthesis. Ideally the magnetic keeper abutments will be threaded onto implants and magnets will be embedded in the prosthesis [21]. The plan of placing two magnets on either side of the standard abutment constituted unique design for this case. The patient indicated that the nasal prosthesis reduced selfconsciousness and was comfortable to wear without any type of irritation to the surrounding skin. The patient was pleased with her appearance and no longer found the need to wrap a cloth around her face.

\section{References}

1. Guttal SS, Patil NP, Thakur S, Kumar MV, Kulkarni S, et al. (2009) Implant-Retained Nasal Prosthesis for a Patient Following Partial Rhinectomy: A Clinical Report . J Prosthodont 18: 353-358.

2. Kumar S, Rajtilak G, Rajasekar V, Kumar M (2013) Nasal prosthesis for a patient with xeroderma pigmentosum. J Pharm Bioallied Sci 5: 176-178.

3. Marunick MT, Harrison R, Beumer J (1985)Prosthodontic rehabilitation of midfacial defects. J Prosthet Dent 54: 553-560.

4. Buzayan MM (2014) Prosthetic management of mid-facial defect with magnet-retained silicone prosthesis. Prosthet Orthot Int 38: 62-67.

5. Jain S, Maru K, Shukla J, Vyas A, Pillai R, et al. (2011) Nasal prosthesis rehabilitation: a case report. J Indian Prosthodont Soc 11: 265-269.

6. Anantharaju A, Kamath G, Mody P, Nooji D (2011) Prosthetic rehabilitation of Oro-nasal defect. J Indian Prosthodont Soc 11: 242-245.

7. Shimamoto $H$, Chindasombatjaroen J, Kakimoto $N$, Kishino $M$, Murakami S, et al. (2012) Perineural spread of adenoid cystic carcinoma in the oral and maxillofacial regions: evaluation with contrast-enhanced CT and MRI. Dentomaxillofac Radiol 41: 143-151.

8. Saunders RCH (1941) The gunner with the silver mask. Am Med Hist 3: 283-285.

9. Kazanjian VH, Rowe AT, Young HA (1932) Prosthesis of the mouth and face. J Dent Res 12: 651-693.

10. Kazanjian VH (1925)Treatment of nasal deformities. J Am Med Assoc 84: 177.

11. Bulbulian AH (1973) Facial Prosthetics. Springfield IL Ed 1: 364-367.

12. Rodrigues S, Shenoy VK, Shenoy K (2005) Prosthetic rehabilitation of a patient after partial rhinectomy: a clinical report. J Prosthet Dent 93: $125-128$.

13. Guttal SS, Patil NP, Shetye AD (2006) Prosthetic rehabilitation of a midfacial defect resulting from lethal midline granuloma: a clinical report. J Oral Rehabil 33: 863-867.

14. Parel SM (1980) Diminishing dependence on adhesive for retention of facial prosthesis. J Prosthet Dent 43:552-560.

15. Parel SM, Branemark PI, Tjellstrom A, Gion G (1986) Osseointegration in maxillofacial prosthetics. Part II: extraoral applications. J Prosthet Dent 55: 600-606.

16. Brånemark PI, Adell R, Breine U, Hansson BO, Lindström J, et al. (1969) Intra-osseous anchorage of dental prostheses. I. Experimental studies. Scand J Plast Reconstr Surg 3: 81-100.

17. Nishimura RD, Roumanas E, Moy PK, Sugai T, (1996) Nasal defects and osseointegrated implants: UCLA experience. J Prosthet Dent 76: 597-602.

18. Kose R, Okur MI, (2009) Reconstruction of the defects in the middle of the nose with subcutaneous pedicled nasolabial island flap: report of two cases. Kulak Burun Bogaz Ihtis Derg 19: 272-276

19. Sashi Purna CR, Annapurna PD, Ahmed SB, Vurla S, Nalla S, et al.(2013) Two-piece nasal septum prosthesis for a large nasal septum perforation: a clinical report. J Prosthodont 22: 143-147.

20. Goveas R, Puttipisitchet O, Shrestha B, Thaworanunta S, Srithavaj ML, et al. (2012) Silicone nasal prosthesis retained by an intranasal stent: a clinical report. J Prosthet Dent 108: 129-132.

21. Kara O, Demir N, Ozturk AN, Keskin M (2015) Implant retained nasal prosthesis. Eur J Prosthodont 3: 23-25. 